\title{
WC-CO COATINGS AND SINTERS MODIFIED WITH NANO-SIZED TIC MICROSTRUCTURE - QUANTITATIVE EVALUATION
}

\author{
Hanna Myalska' ${ }^{1}$ Bartłomiej Dybowski ${ }^{1}$, Grzegorz Moskal ${ }^{1}$ \\ 1 Institute of Materials Science, Silesian University of Technology, Krasińskiego Street 8, 40-019 Katowice, \\ Poland, e-mail: hanna.myalska@polsl.pl
}

Received: 2016.12 .15 Accepted: 2017.02.01 Published: 2017.03.01

\begin{abstract}
The different concepts of WC-Co thermally sprayed coatings improvement may be considered and the application of nanoparticles, as the mechanical strengthening addition, is one of them. Nanostructured WC-Co coatings are characterized by higher hardness than the coatings formed from micrometric WC grains; whereas coatings with bimodal distribution of particles reveal greater wear resistance than the coatings obtained exclusively from nano-sized powders. Mixed effect of the matrix reinforcement by nanoparticles and strong fix of the micron-sized WC grains was proposed as a possible reason for enhanced wear resistance of bimodal coatings. In order to obtain a bimodal distribution of particles in the material standard WC-Co (83-17) powder was mixed with nanometric $\mathrm{TiC}$ powder $(40-100 \mathrm{~nm})$. The amount of $\mathrm{TiC}$ in powder mixtures was in the range from 1 to $7 \mathrm{wt} . \%$. The mixtures were deposited on steel substrate using HVAF method and also hot pressed in vacuum. The microstructure of obtained coatings and sinters was quantitatively evaluated. Sinters revealed more homogenous distribution of the nano-sized TiC particles than the coatings. The addition of nano-sized $\mathrm{TiC}$ in the case of coatings has led to the decrease of its porosity. The agglomeration of nano-sized TiC particles in the coatings results in the decrease of material's hardness.
\end{abstract}

Keywords: coatings, nanoparticles, TiC, WC-Co, quantitative evaluation.

\section{INTRODUCTION}

Cemented carbides, such as WC-Co, are widely applied as cutting, forming and machining tools in the various areas of industry due to their high hardness, good fracture toughness and great wear resistance $[1,3]$. These properties are achieved by the complex composite structure. Hard, brittle carbides, usually WC, are uniformly distributed in ductile metallic matrix, usually Co $[2,20]$.

WC-Co cermet coatings are commonly used to enhance wear resistance of mechanical components. Thermal spraying is one of the most well-known technologies applied in order to obtain WC-Co coatings. These technology includes typically air plasma spraying (APS) and more recently high velocity oxy-fuel (HVOF) and high velocity air-fuel (HVAF) spraying [18].
High velocity oxy-fuel spraying process is suitable to obtain dense cermet coatings with low oxidation resulting from heating the feedstock powder to near or above its melting point, at a relatively low process temperature [21, 22]. Due to high velocity, short time of interaction between the powder and the flame and in conjunction with process temperature, which limits thermal alteration should ensure good cohesion, low porosity and low decarburization $[4,6]$. Other process applied as an alternative to HVOF process, is the high velocity air fuel (HVAF) process, where instead of oxygen, compressed air is used for combustion. HVAF process operates at lower temperatures. Replacement of pure oxygen by compressed air reduces the costs of coatings deposition and also reduces oxidation or decarburization effects after spraying $[7,9,11]$. 
Table 1. The Parameters of coatings deposition $\backslash$

\begin{tabular}{|c|c|c|c|c|c|c|c|}
\hline \multicolumn{2}{|c|}{ Oxygen } & \multicolumn{2}{|c|}{ Air } & \multicolumn{2}{|c|}{ Nitrogen } & \multirow{2}{*}{$\begin{array}{l}\text { Powder } \\
\text { feed rate } \\
\text { [rpm] }\end{array}$} & \multirow{2}{*}{$\begin{array}{l}\text { Surface } \\
\text { speed } \\
{[\mathrm{mm} / \mathrm{s}]}\end{array}$} \\
\hline Pressure [bar] & Flow [1/min] & Pressure [bar] & Flow [1/min] & Pressure [bar] & Flow [1/min] & & \\
\hline 8.5 & 75 & 9.2 & 85 & 8.4 & 30 & $3 \div 7$ & 500 \\
\hline
\end{tabular}

Literature data $[13,15,23]$ suggests the improvement of coatings properties by using nanostructured powders. Higher hardness, strength, toughness and abrasion resistance than the conventional counterpart was reported in coatings obtained from nanostructured WC-Co feedstock powder due to the size effect $[17,24]$. However, other authors $[5,15]$ revealed a decrease of sliding and abrasive wear resistance of nanostructured WC-Co coatings.

The introduction of nano-sized particles and fibers could be an efficient method to increase hardness and toughness of coatings, because of the bimodal distribution of particles in the matrix $[8,10,14,16]$.

Therefore, it is worth exploring whether improvement of the HVAF deposited coatings can be achieved when nano-sized particles with different phase composition are applied as WC-Co powder addition. Previous work [12] revealed an influence of nano-sized TiC on phase composition of HVOF and HVAF thermally sprayed coatings.

In this work, the influence of nano-sized TiC addition on microstructure and morphology of WC-Co coatings and sinters was examined. Standard WC-17Co powder was modified with various amounts of $\mathrm{TiC}$ addition. The aim of this study was to examine the improvement of uniformity of the microstructure, possibility of porosity reduction and increase of hardness. Furthermore, application of hot vacuum pressing will reveal an influence of technology on nano-sized TiC behavior in WC-Co feedstock powder.

\section{MATERIAL AND METHODS}

High velocity air fuel (HVAF) technique and hot vacuum pressing were applied in order to obtain from WC-Co with nano-sized $\mathrm{TiC}$ powder mixtures. A mechanically blended mixtures of WC-17Co standard powder (Amperit 526.074, FST) with nano-sized TiC (Hefei EvNano Technology) was in fact prepared. The particle size of applied initial powders was $45 / 15 \mu \mathrm{m}$ for WC-17Co and 40-100 $\mathrm{nm}$ for TiC. The mixtures contained different TiC weight amounts as follow: $1 \%, 3 \%, 5 \%$ and $7 \%$, respectively. These mixtures were deposited using HVAF method with the thermal spraying parameters presented in Table 1. The surface of substrate, in the form of sheets with sizes of $40 \times 40 \times 4 \mathrm{~mm}$, was prepared in accordance with the parameters used for thermal spraying technologies. The sinters obtained from these powder mixtures were hot pressed in Degussa press at $1300^{\circ} \mathrm{C}$ under pressure of 15 $\mathrm{MPa}$ for 30 minutes under vacuum.

Microstructural characterization and element maps of obtained coatings and sinters using EDS system were carried out with HITACHI S-4200 scanning electron microscope with 5000 magnification. Amount of individual elements, such as porosity, $\mathrm{WC}, \mathrm{TiC}$ and $\mathrm{Co}$, was estimated on cross-sectioned samples by quantitative evaluation on SEM images with Met-Ilo software [19]. The procedure for the quantitative evaluation of the microstructure is given in the Table 2. Samples micro-hardness was also determined on crosssection by the Vickers method with Microhardness Tester FM-800 under indentation of $100 \mathrm{~g}$. At least 10 indentations were conducted on each cross section.

\section{RESULTS}

The results of the microstructure investigations and selected elements mapping using EDS technique are shown in Figures 1-8. For all obtained materials an uniform distribution of carbon was recorded. Carbon is a light element with a low energy of characteristic radiation. As a result, the quantitative or semiquantitative evaluation of such element by the EDS method is impossible. That is why the investigated distribution of $\mathrm{C}$ among the microstructure seems to be uniform.

In the sinter and coating, formed from an initial powder mixture of WC-Co $+1 \mathrm{wt} . \%$ $\mathrm{TiC}$, differences in microstructure and elements distribution were observed (Fig. 1,2). In the sinter, WC grains were forming clusters 
Table 2. Procedure for the quantitative evaluation of the materials microstructure

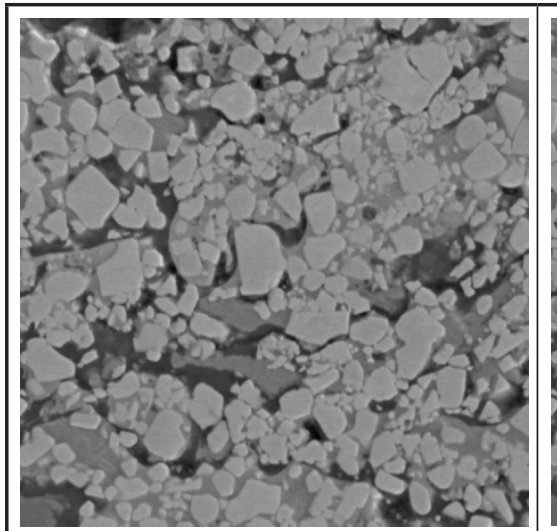

Image A: Input image;

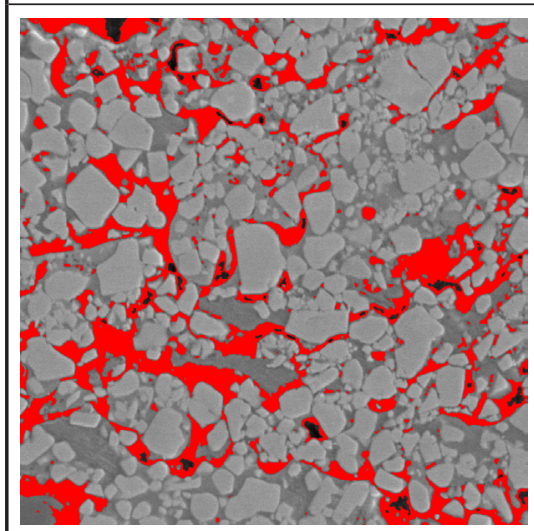

Image d: Dark regions detection, subtraction of image $b$, evaluation of TiC parameters;

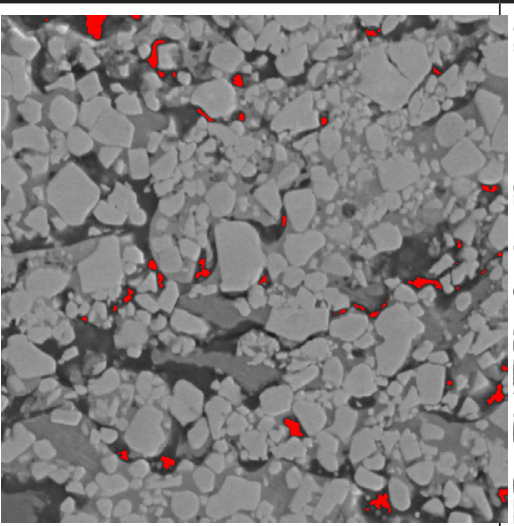

Image b: Porosity detection, evaluation;

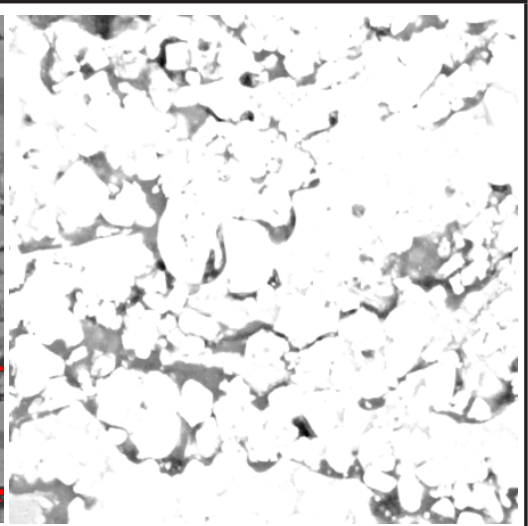

Image C: Addition of 160 constant to the Image A, histogram normalization;

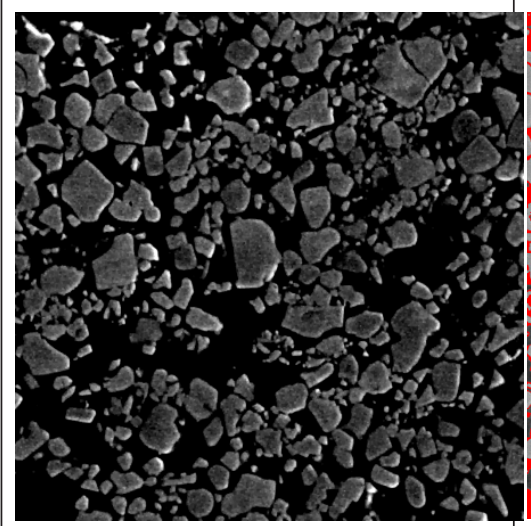

Image E: Constant subtraction from Image $A$, followed by image multiplying by 5. The subtracted value is dependent on the overall image brightness;

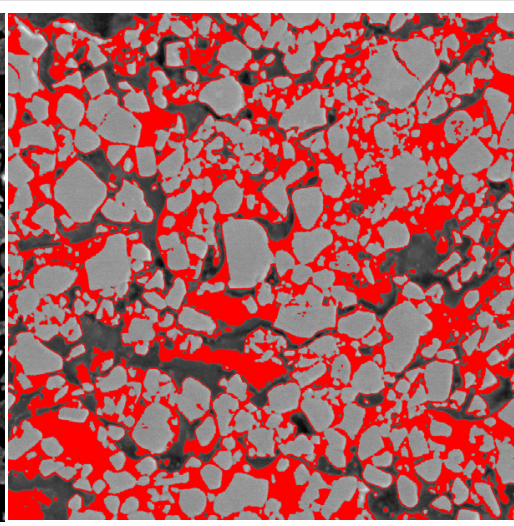

Image f: Detection of dark regions, subtraction of images $b$ and $d$, evaluation of Co matrix parameters;

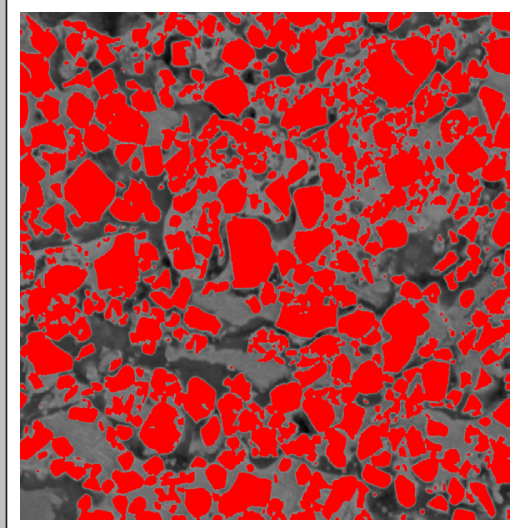

Image g: Detection of bright regions of the image A, subtraction of images $b, d$ and $f$. Evaluation of the WC parameters.

surrounded by cobalt matrix. Areas enriched with Ti were detected. Such areas in the SEM image are similar to the regions, where only the Co was detected. This is probably due to homogenous distribution of nano-sized $\mathrm{TiC}$ particles within the Co matrix. However, in the coating the signal from $\mathrm{Ti}$ was lower and only fine areas enriched with the element were observed. Moreover, these areas were easily distinguishable in the SEM image. In the case of coating, WC grains were characterized by different size, from 0.5 to $2 \mu \mathrm{m}$, they were not forming clusters and their uniform distribution in cobalt matrix was observed.

In the case of the materials obtained from a powder mixture of WC-Co $+3 \mathrm{wt} . \%$ TiC similar 

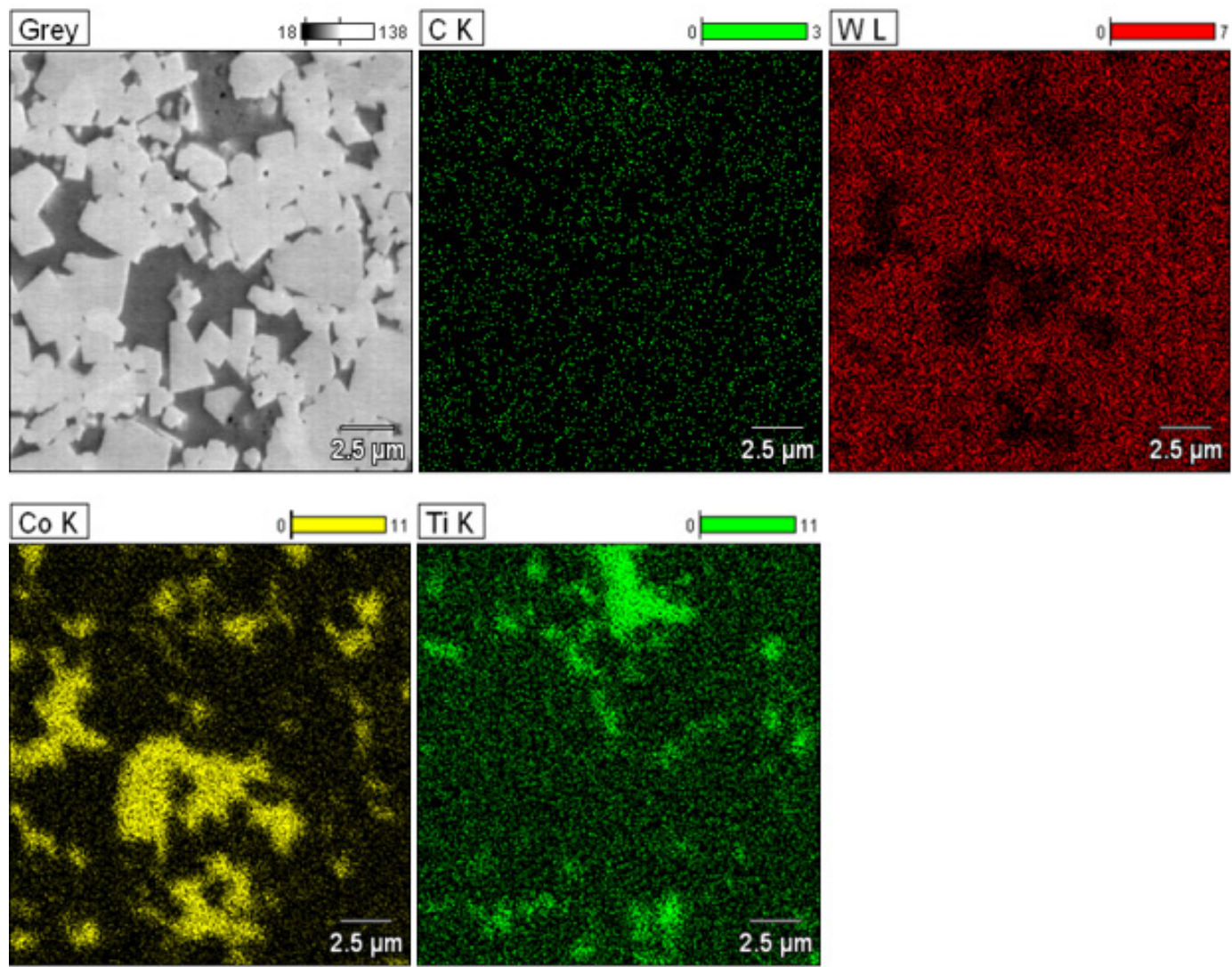

Fig. 1. Microstructure and elements map of carbon, tungsten, cobalt and titanium of the sinter obtained from a powder mixture of WC-Co + 1wt.\% TiC, SEM, EDS
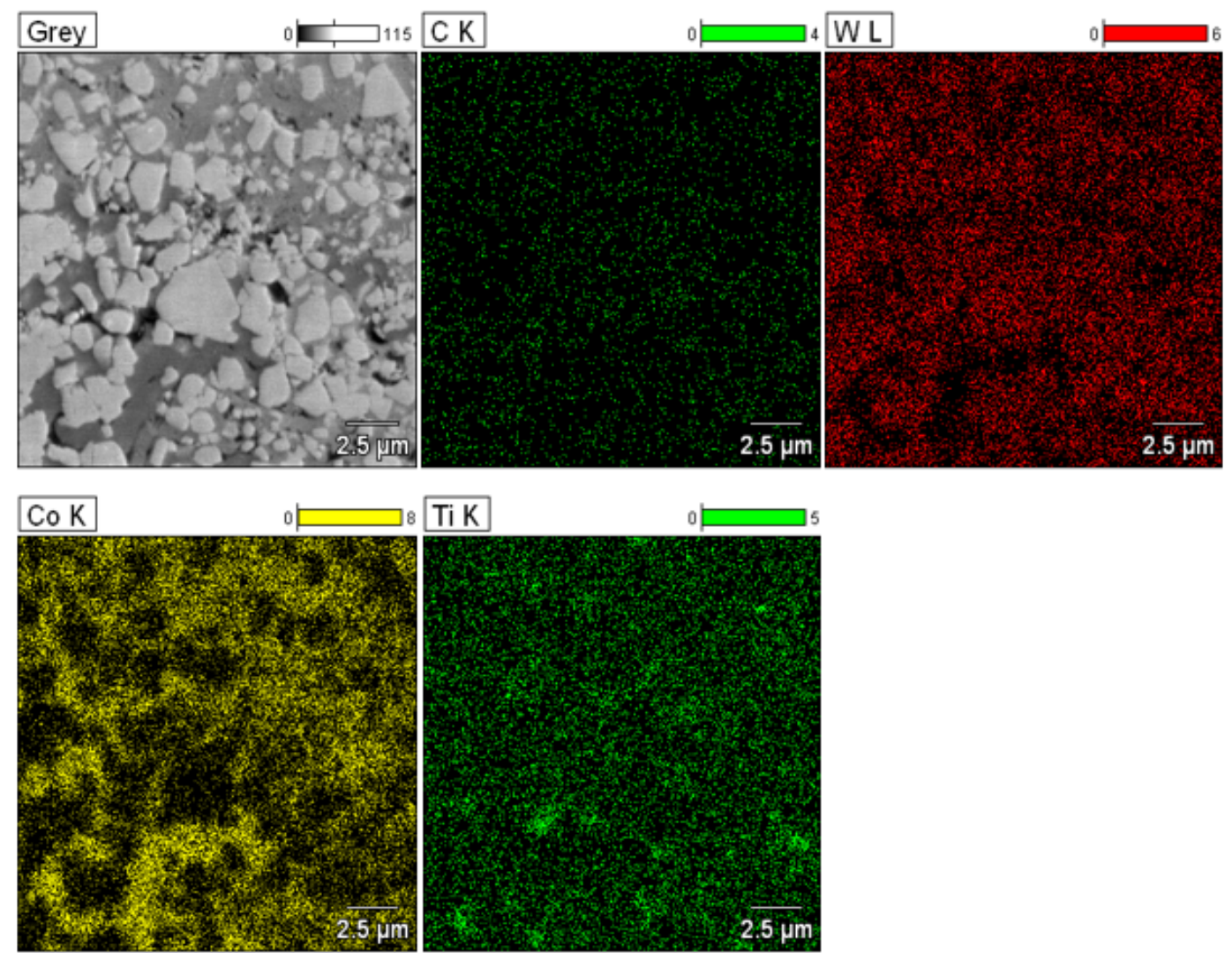

Fig. 2. Microstructure and elements map of carbon, tungsten, cobalt and titanium of the coating obtained from a powder mixture of WC-Co + 1wt.\% TiC, SEM, EDS 
tendency in microstructure formation was observed (Fig. 3, 4). In the sinter the WC grains were forming clusters. Inside the clusters small regions enriched with Co were observed. The sub-micrometric TiC powder started to agglomerate between WC clusters. A signal from Ti was stronger in the case of the sinter. In the coating, no tendency for WC clusters formation was observed.

The same mechanisms of TiC agglomerates formation around the WC clusters were observed for the sinters fabricated from the mixtures of WC-Co $+5 \mathrm{wt} . \% \mathrm{TiC}$ and $\mathrm{WC}-\mathrm{Co}$ +7 wt.\% TiC (Fig. 5-8). With a higher amount of $\mathrm{TiC}$ in initial powder mixture, both the $\mathrm{TiC}$ as well as WC particles revealed greater tendency for agglomeration. The TiC agglomerates started to form cell structure between WC clusters. The clusters were denser comparing to the sinters with lower TiC content and the cobalt phase was present only inside the clusters. Still, some areas of Co matrix are also enriched in Ti. In the case of the coatings lower signal of Ti was detected also. Even with high content of $\mathrm{TiC}$ no clusters of WC were observed. The cobalt matrix was uniformly distributed in the coatings. The TiC agglomerates are usually separated from the Co matrix. However, small areas enriched with both $\mathrm{Ti}$ and Co were detected.

The microhardness results revealed higher hardness of WC-Co + TiC sinters than thermal sprayed coatings (Tab. 3). An increase of microhardness was noticed with an increase of $\mathrm{TiC}$ content in the coatings. The coating deposited from WC-Co+1wt. $\%$ TiC powder mixture was characterized with the lowest microhardness and it was $1113 \mathrm{HV}_{0.1}$. The highest microhardness $\left(1292 \mathrm{HV}_{0.1}\right)$ was observed for the coating containing $7 \mathrm{wt} . \% \mathrm{TiC}$ in the initial powder mixture. However, in the case of the sinters, no correlation between the microhardness and the amount of TiC additive was found. The highest microhardness value was recorded for WC$\mathrm{Co}+3 \mathrm{wt} . \% \mathrm{TiC}$ sinter $\left(2076 \mathrm{HV}_{0.1}\right)$ and the lowest for WC-Co $+1 \mathrm{wt} . \% \mathrm{TiC}$ sinter $\left(1717 \mathrm{HV}_{0.1}\right)$. The microhardness started to decrease, when the amount of $\mathrm{TiC}$ was above $3 \mathrm{wt} . \%$ in initial powder mixture. Observed phenomena of micorohardness and porosity changes is related to the microstructure of obtained materials from WC$\mathrm{Co}$ and $\mathrm{TiC}$ mixtures.

The results of quantitative evaluation of the prepared materials microstructure are given in Table 4 and Figure 9. Volume fraction of TiC agglomerates within the coatings' microstructure increases with an increase of initial fraction of the carbide in the prepared powder mixtures. Except from the sample with $1 \mathrm{wt} . \%$ of nano-sized $\mathrm{TiC}$ in the initial mixture, the coatings conatain smaller TiC volume fraction than the intended one. This is due to loose of some material during the spraying process. In case of sintered powder, evaluated volume fraction of $\mathrm{TiC}$ is much lower than the intended one, the increasing tendency is also much less obvious. Elements mapping (Figs. $1-8$ ) revealed, that $\mathrm{Ti}$ is quite homogenously distributed within the Co matrix, even when it is not observed in the SE image. During the sintering process, nano-sized $\mathrm{TiC}$ particles do not tend to agglomerate. They are entrapped within the Co matrix as a nano-particles. In case of the coating, TiC forms significant agglomerates during spraying, which can be also observed in the elements mapping. Agglomerates are easily distinguishable by the SEM method. This can be confirmed by the measurement of the mean surface area of both $\mathrm{TiC}$ agglomerates as well as the surface area of Co matrix flat section. In case of the coating, surface area of $\mathrm{TiC}$ agglomerates increases with an increase of introduced TiC, while in the sinter, their surface area is constant. On the other hand, in case of sintered powder, the mean surface area of Co matrix flat section is increasing with an increase of introduced $\mathrm{TiC}$ fraction. In the sintered powder, nano-sized TiC is uniformly distributed within the Co matrix, reinforcing it. Thus, the increase of $\mathrm{TiC}$ nanoparticles fraction may result in increase of the size and volume fraction of $\mathrm{Co}$ matrix reinforced with nano-sized TiC.

The porosity of the sintered material is relatively constant, while porosity of the coatings is strongly affected by the fraction of nano-sized TiC introduced to the material. Coatings' poros-

Table 3. Microhardness of the obtained materials

\begin{tabular}{|c|c|c|c|c|c|c|c|c|}
\hline \multirow{2}{*}{$\begin{array}{c}\text { Powder } \\
\text { mixture } \\
\text { composition }\end{array}$} & \multicolumn{2}{|c|}{ WC-Co+1wt.\% TiC } & \multicolumn{2}{|c|}{ WC-Co+3wt.\% TiC } & \multicolumn{2}{c|}{ WC-Co+5wt.\% TiC } & \multicolumn{2}{c|}{ WC-Co+7wt.\% TiC } \\
\cline { 2 - 9 } & Sinter & Coating & Sinter & Coating & Sinter & Coating & Sinter & Coating \\
\hline $\begin{array}{c}\text { Hardness, } \\
\text { HV }_{0.1}\end{array}$ & $1717 \pm 178$ & $1113 \pm 86$ & $2076 \pm 120$ & $1120 \pm 64$ & $2043 \pm 120$ & $1216 \pm 62$ & $1991 \pm 122$ & $1292 \pm 87$ \\
\hline
\end{tabular}



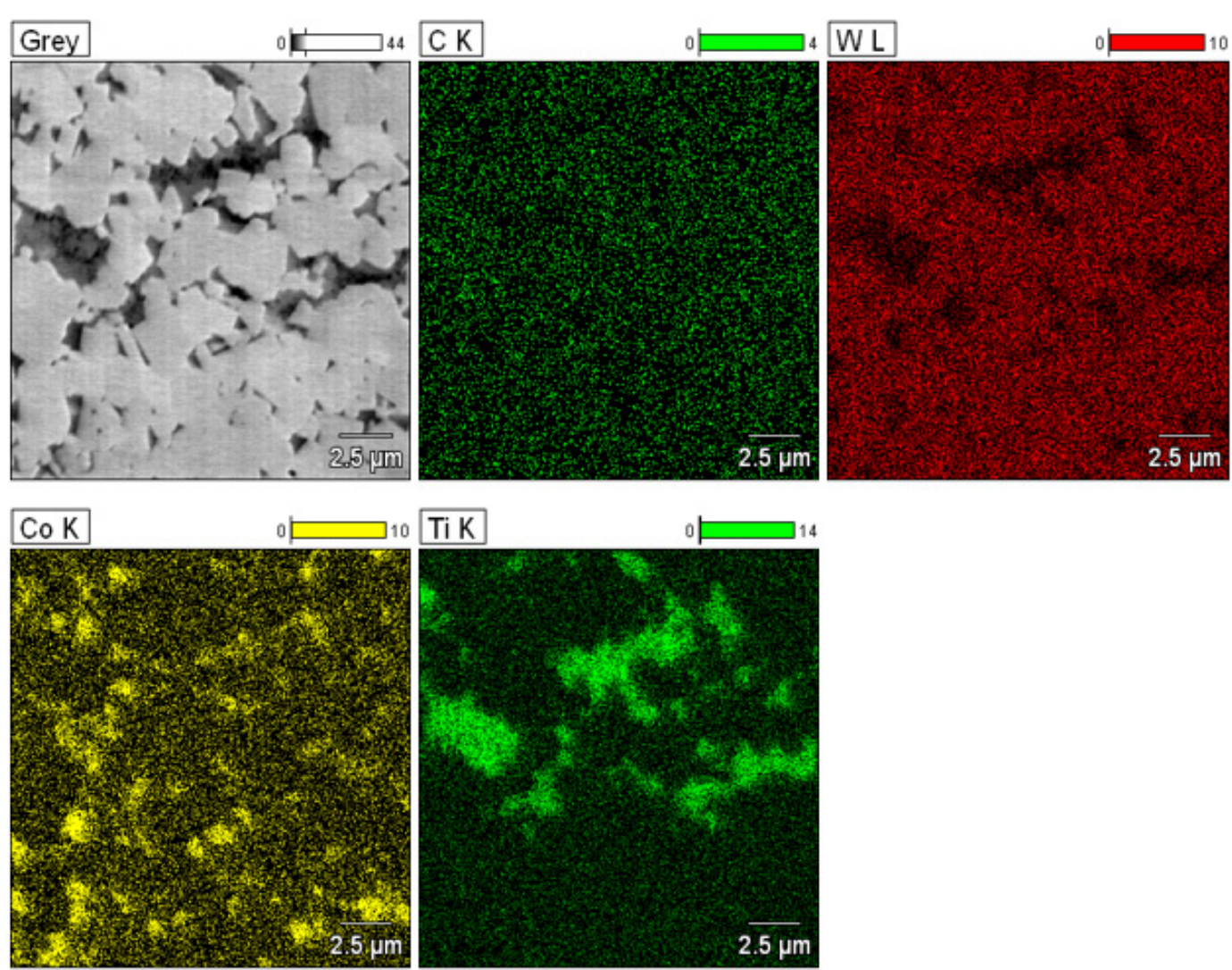

Fig. 3. Microstructure and elements map of carbon, tungsten, cobalt and titanium of the sinter obtained from a powder mixture of WC-Co + 3wt.\% TiC, SEM, EDS
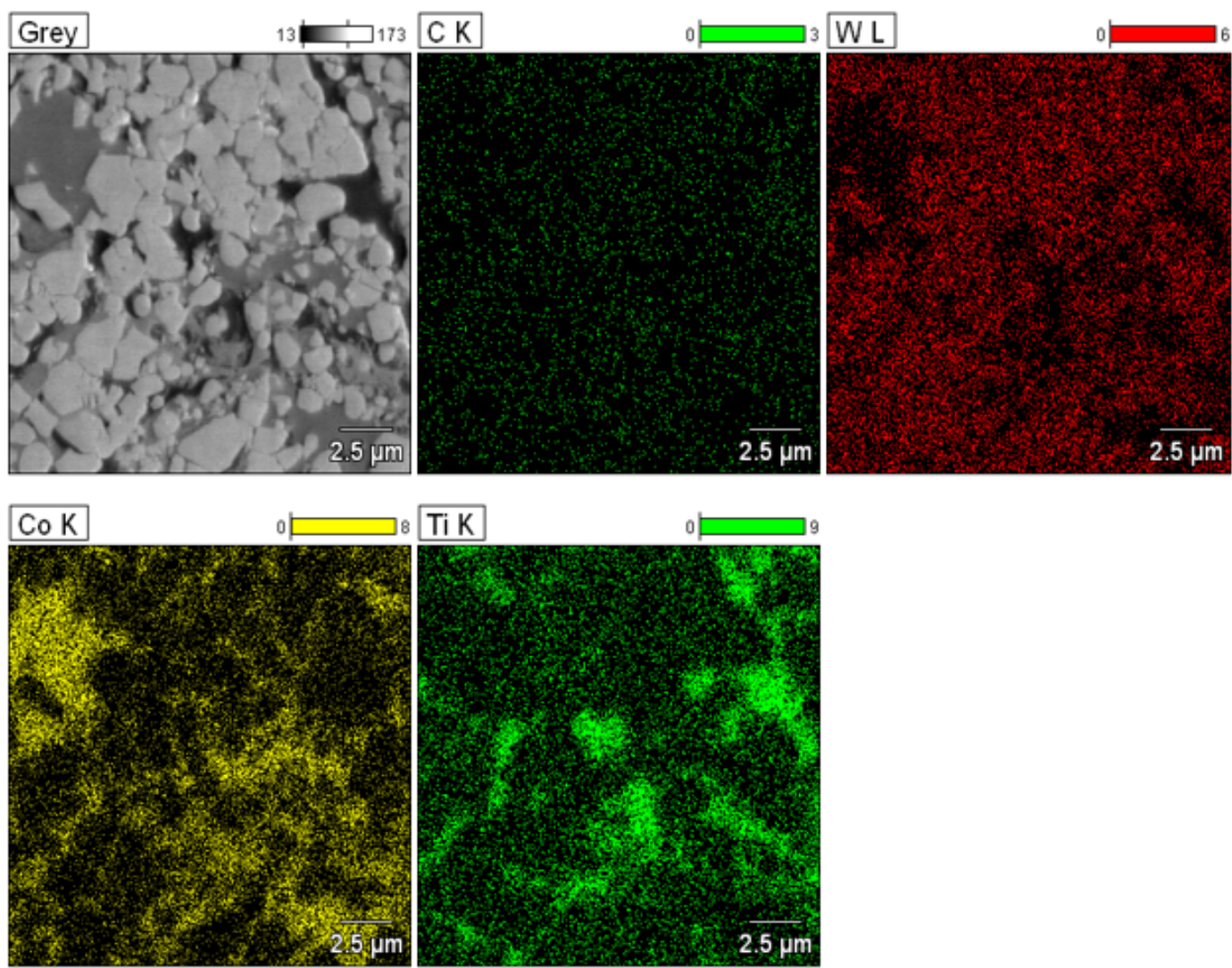

Fig. 4. Microstructure and elements map of carbon, tungsten, cobalt and titanium of the coating obtained from a powder mixture of WC-Co + 3wt.\% TiC, SEM, EDS 

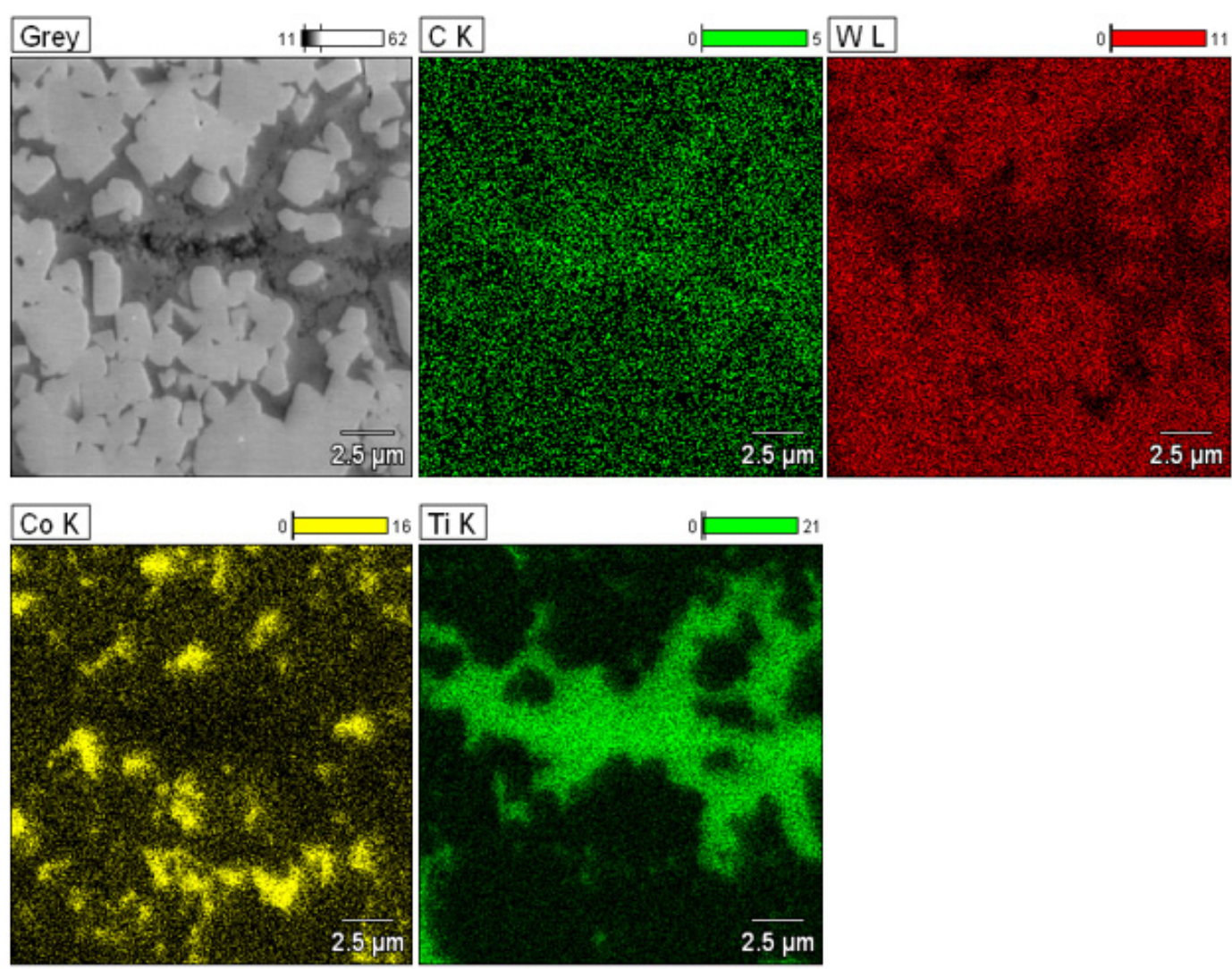

Fig. 5. Microstructure and elements map of carbon, tungsten, cobalt and titanium of the sinter obtained from a powder mixture of WC-Co + 5wt.\% TiC, SEM, EDS
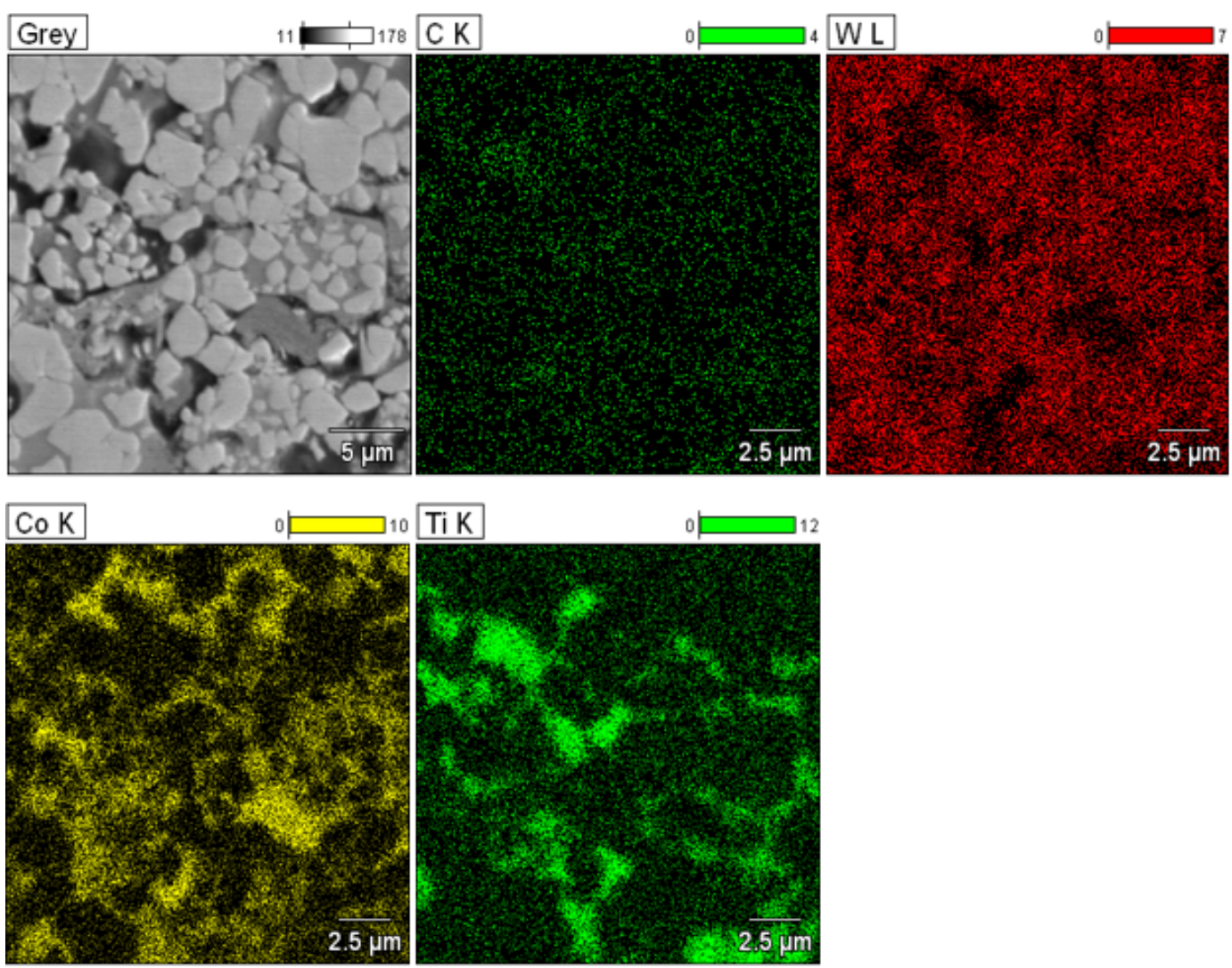

Fig. 6. Microstructure and elements map of carbon, tungsten, cobalt and titanium of the coating obtained from a powder mixture of WC-Co + 5wt.\% TiC, SEM, EDS 

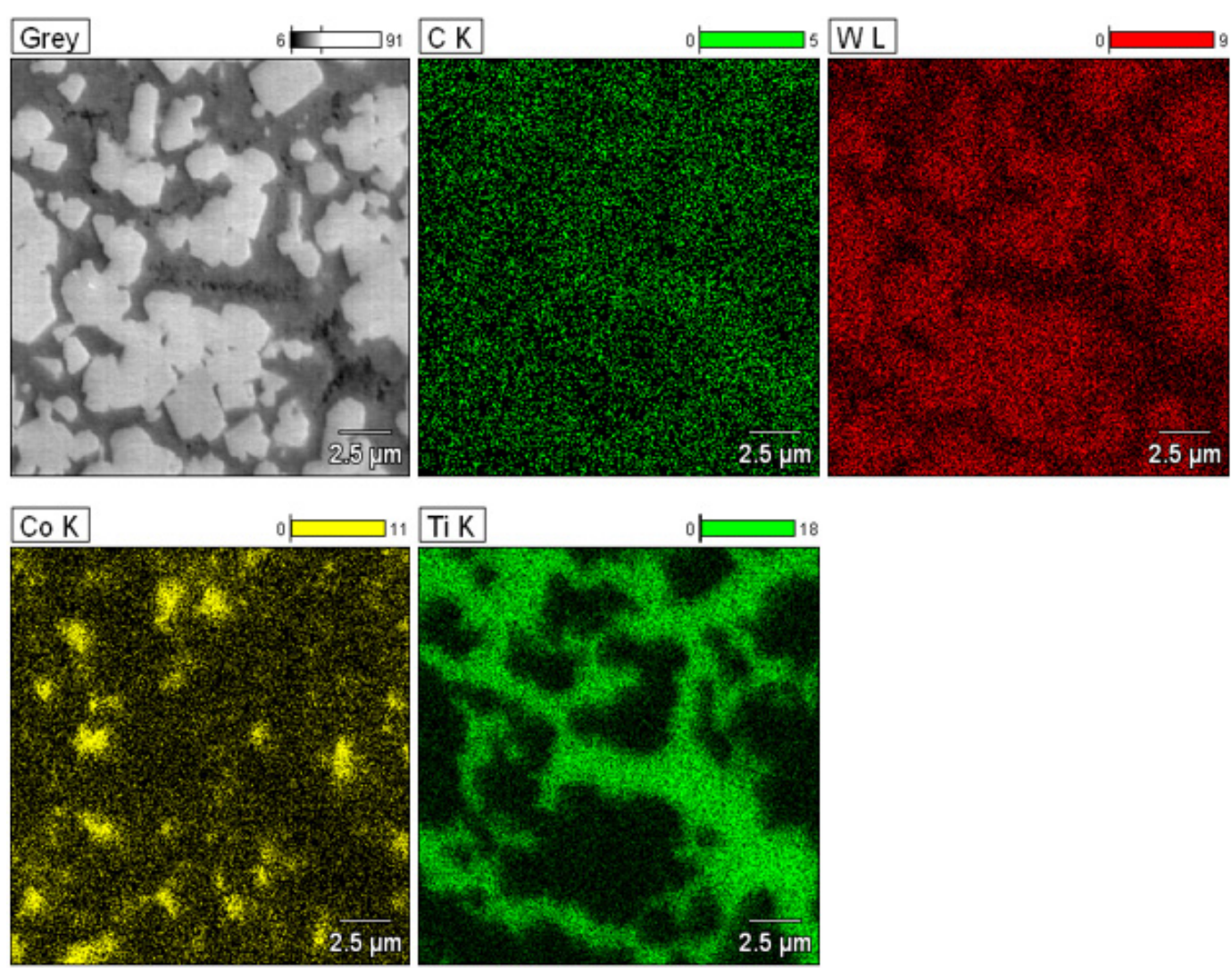

Fig. 7. Microstructure and elements map of carbon, tungsten, cobalt and titanium of the sinter obtained from a powder mixture of WC-Co + 7wt.\% TiC, SEM, EDS
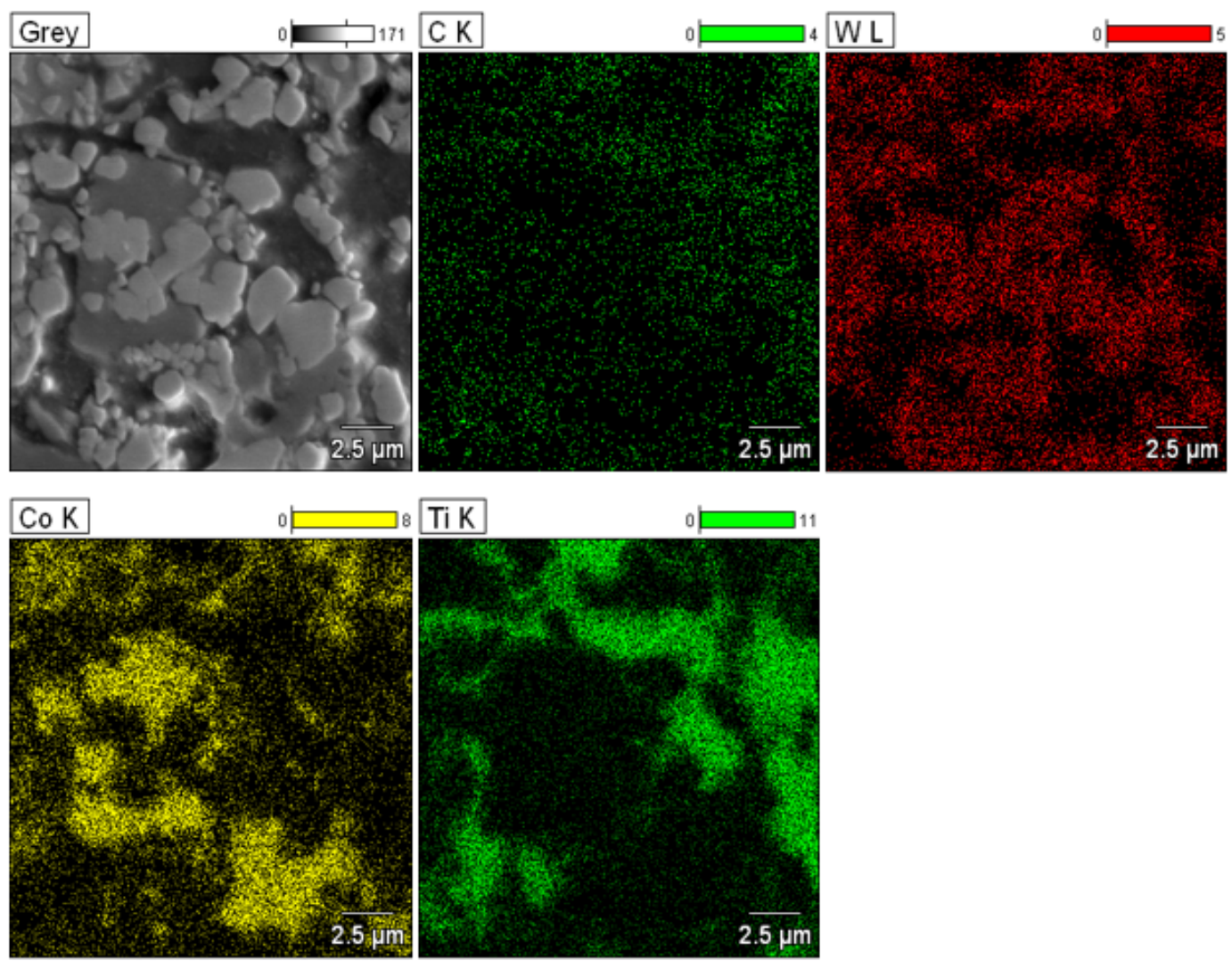

Fig. 8. Microstructure and elements map of carbon, tungsten, cobalt and titanium of the coating obtained from a powder mixture of WC-Co $+7 \mathrm{wt} . \%$ TiC, SEM, EDS 
Table 4. The results of the quantitative evaluation of the prepared materials microstructure

\begin{tabular}{|c|c|c|c|c|c|c|c|c|}
\hline & \multicolumn{4}{|c|}{ Sinters } & \multicolumn{4}{|c|}{ Coatings } \\
\hline Sample & $\begin{array}{c}\text { WC- } \\
\text { Co } \\
+ \\
1 \text { wt. } \% \\
\text { TiC }\end{array}$ & $\begin{array}{c}\text { WC- } \\
\text { Co } \\
+ \\
3 \text { wt. } \% \\
\text { TiC }\end{array}$ & $\begin{array}{c}\text { WC- } \\
\text { Co } \\
+ \\
5 \text { wt. } \\
\% \text { TiC }\end{array}$ & $\begin{array}{c}\text { WC- } \\
\text { Co } \\
+ \\
7 \text { wt. } \% \\
\text { TiC }\end{array}$ & $\begin{array}{c}\text { WC- } \\
\text { Co } \\
+ \\
1 \text { wt. } \% \\
\text { TiC }\end{array}$ & $\begin{array}{c}\text { WC- } \\
\text { Co } \\
+ \\
3 \text { wt. } \% \\
\text { TiC }\end{array}$ & $\begin{array}{c}\text { WC- } \\
\text { Co } \\
+ \\
5 \text { wt. } \% \\
\text { TiC }\end{array}$ & $\begin{array}{c}\text { WC- } \\
\text { Co } \\
+ \\
7 \text { wt. } \% \\
\text { TiC }\end{array}$ \\
\hline Volume fraction of the introduced TiC [\%] & 2.87 & 8.31 & 13.35 & 18.05 & 2.87 & 8.31 & 13.35 & 18.05 \\
\hline Mass fraction of the introduced TiC [\%] & 1 & 3 & 5 & 7 & 1 & 3 & 5 & 7 \\
\hline \multicolumn{9}{|c|}{$\mathrm{TiC}$} \\
\hline Volume fraction $V_{v}[\%]$ & 0.478 & 4.363 & 2.775 & 5.365 & 3.22 & 6.73 & 12.5 & 14.3 \\
\hline Variability factor [\%] & 191 & 86.06 & 69.01 & 118.6 & 54.4 & 32.8 & 24.1 & 31.9 \\
\hline Surface area of the flat section $A\left[\mu \mathrm{m}^{2}\right]$ & 0.0173 & 0.0370 & 0.0249 & 0.0447 & 0.028 & 0.065 & 0.135 & 0.216 \\
\hline Variability factor [\%] & 190.6 & 1038 & 244.7 & 778.1 & 172 & 239 & 350 & 348 \\
\hline Distance between $\mathrm{TiC}$ agglomerates I [ $\mu \mathrm{m}]$ & 0.64 & 0.466 & 0.465 & 0.447 & 0.474 & 0.522 & 0.578 & 0.683 \\
\hline Variability factor [\%] & 113.2 & 58.18 & 59.06 & 61.63 & 86.7 & 51.2 & 51 & 51.7 \\
\hline Elongation factor [-] & 1.785 & 1.824 & 1.839 & 1.808 & 1.81 & 1.9 & 1.92 & 1.92 \\
\hline Variability factor [\%] & 27.68 & 29.87 & 31.2 & 28.85 & 29.1 & 31.9 & 33.8 & 31.9 \\
\hline \multicolumn{9}{|c|}{ Porosity } \\
\hline Volume fraction $V_{v}[\%]$ & 0.131 & 0.22 & 0.114 & 0.116 & 0.793 & 0.761 & 0.658 & 0.118 \\
\hline Variability factor [\%] & 103.4 & 71.77 & 80.75 & 102.8 & 20.4 & 75.2 & 85.8 & 93.3 \\
\hline Surface area of the flat section $A\left[\mu \mathrm{m}^{2}\right]$ & 0.0093 & 0.0086 & 0.0112 & 0.0167 & 0.027 & 0.023 & 0.038 & 0.023 \\
\hline Variability factor [\%] & 218.1 & 192.1 & 158.5 & 176.6 & 174 & 197 & 185 & 160 \\
\hline Distance between pores I [ $\mu \mathrm{m}]$ & 0.949 & 0.677 & 1.019 & 1.17 & 0.469 & 0.75 & 0.929 & 1.67 \\
\hline Variability factor [\%] & 111.6 & 140.6 & 151.7 & 129.9 & 61 & 98 & 91 & 120 \\
\hline Elongation factor [-] & 1.666 & 1.599 & 1.633 & 1.654 & 1.67 & 1.72 & 1.75 & 1.75 \\
\hline Variability factor [\%] & 27.37 & 22.89 & 23.28 & 27.08 & 25.3 & 27.6 & 27.7 & 27.2 \\
\hline \multicolumn{9}{|c|}{ Co matrix } \\
\hline Volume fraction $V_{v}[\%]$ & 12.78 & 17.03 & 23.59 & 35.56 & 36.3 & 37.8 & 31.8 & 31.3 \\
\hline Variability factor [\%] & 45.06 & 25.07 & 12.78 & 20.04 & 12.6 & 11.8 & 15.3 & 18.6 \\
\hline Surface area of the flat section $A\left[\mu \mathrm{m}^{2}\right]$ & 0.108 & 0.163 & 0.288 & 0.648 & 0.315 & 0.465 & 0.39 & 0.427 \\
\hline Variability factor [\%] & 527 & 603 & 838.4 & 966.2 & 1093 & 1177 & 1053 & 988 \\
\hline Distance between Co matrix I [ $\mu \mathrm{m}]$ & 0.553 & 0.583 & 0.615 & 0.69 & 0.469 & 0.509 & 0.556 & 0.576 \\
\hline Variability factor [\%] & 45.85 & 43.49 & 48.21 & 60.36 & 61 & 69.6 & 60.5 & 60.1 \\
\hline Elongation factor [-] & 1.84 & 1.861 & 1.887 & 1.874 & 1.92 & 1.89 & 2.03 & 1.89 \\
\hline Variability factor [\%] & 32.28 & 31 & 33.27 & 35.01 & 35.2 & 37.5 & 48.8 & 38.3 \\
\hline \multicolumn{9}{|c|}{ WC } \\
\hline Volume fraction $V_{v}[\%]$ & 85.66 & 82.03 & 75.37 & 63.83 & 58.1 & 54.7 & 55.1 & 54.3 \\
\hline Variability factor [\%] & 5.772 & 5.045 & 4.011 & 10.73 & 7.12 & 7.94 & 7.27 & 9.3 \\
\hline Surface area of the flat section $A\left[\mu \mathrm{m}^{2}\right]$ & 10.9 & 10.12 & 4.153 & 2.013 & 0.466 & 0.444 & 0.589 & 0.773 \\
\hline Variability factor [\%] & 430.7 & 430.1 & 507.9 & 478.8 & 1064 & 721 & 663 & 744 \\
\hline Distance between WC particles I [ [ $\mathrm{m}]$ & 1.286 & 1.552 & 1.141 & 0.844 & 0.463 & 0.5 & 0.564 & 0.613 \\
\hline Variability factor [\%] & 137 & 95.53 & 86.54 & 82.85 & 62.5 & 54.2 & 53.5 & 60 \\
\hline Elongation factor [-] & 1.633 & 1.855 & 1.822 & 1.767 & 1.64 & 1.68 & 1.7 & 1.69 \\
\hline Variability factor [\%] & 26.98 & 43.59 & 40.27 & 42.09 & 28.3 & 32.3 & 29.2 & 29.4 \\
\hline
\end{tabular}


ity decreases with the increase of nano-sized TiC amount, reaching porosity of sintered material at $7 \mathrm{wt} . \%$ of TiC. Also, with the increasing volume fraction of $\mathrm{TiC}$, distance between the pores in deposited coating increases.

The hardness of sintered material is higher than the hardness of deposited coating. Considering WC-Co $+7 \mathrm{wt} . \%$ TiC mixture, the porosity of the sintered material and deposited coating is similar and their hardness strongly differs, it has to be affected by the other microstructural factor. The most likely distribution of the nano-sized TiC within the Co matrix is crucial. The large agglomerates of nano-particles do not efficiently strengthen the material. On the other hand, fine reinforcement of the Co matrix in the sintered powders leads to significant increase of the material's hardness.

\section{CONCLUSIONS}

The presented research was focused on the modification of WC-Co sinters and coatings microstructure. Two fabrication methods for obtaining WC-Co materials modified with TiC nanopowder were analyzed. One of them was hot pressed in vacuum and the other one was thermal spraying using HVAF method. The influence of a)

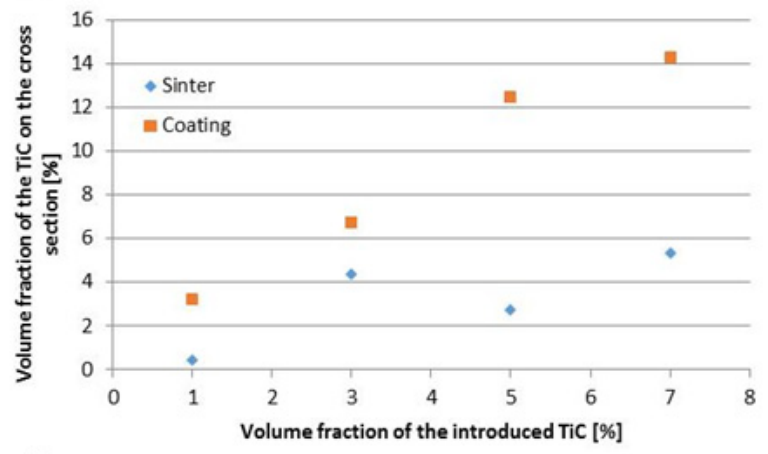

c)

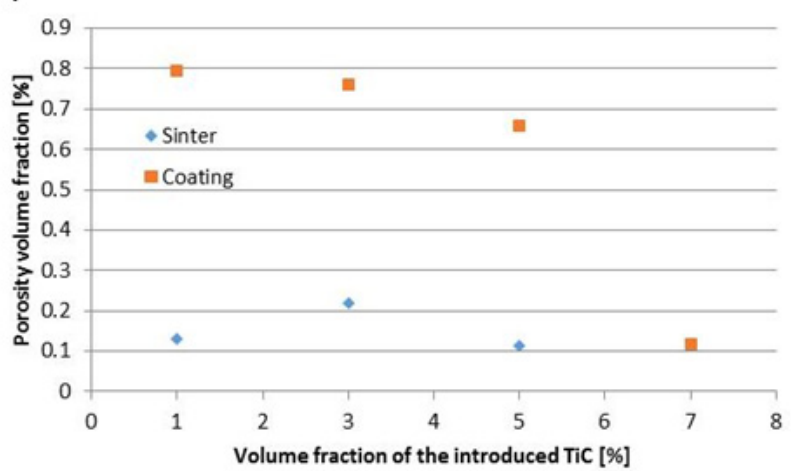

e)

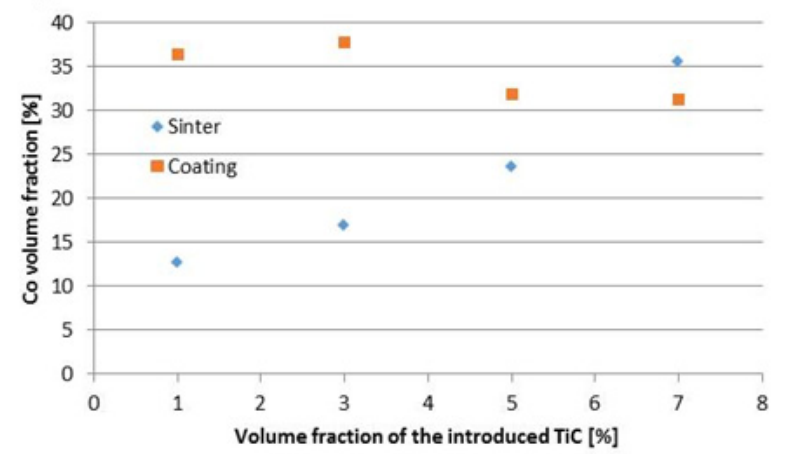

b)

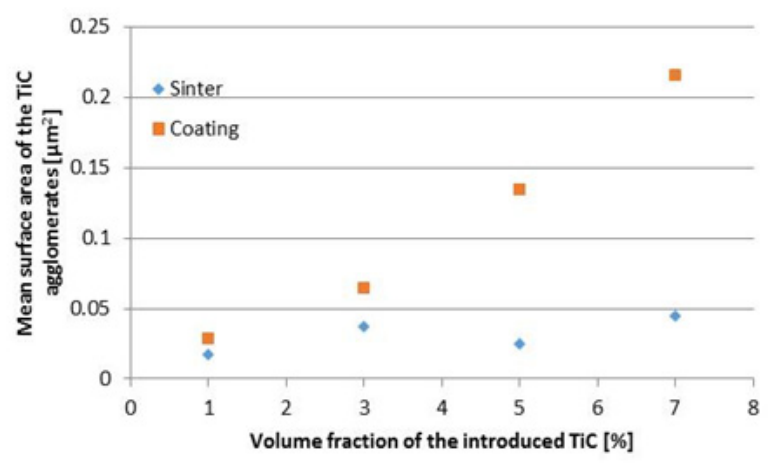

d)

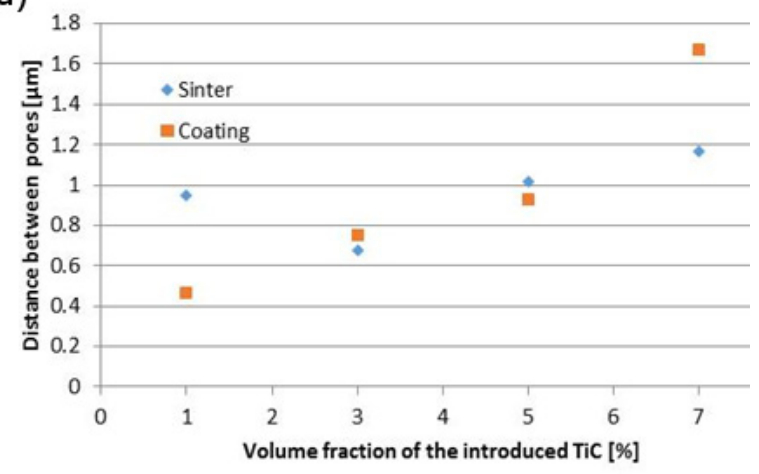

f)

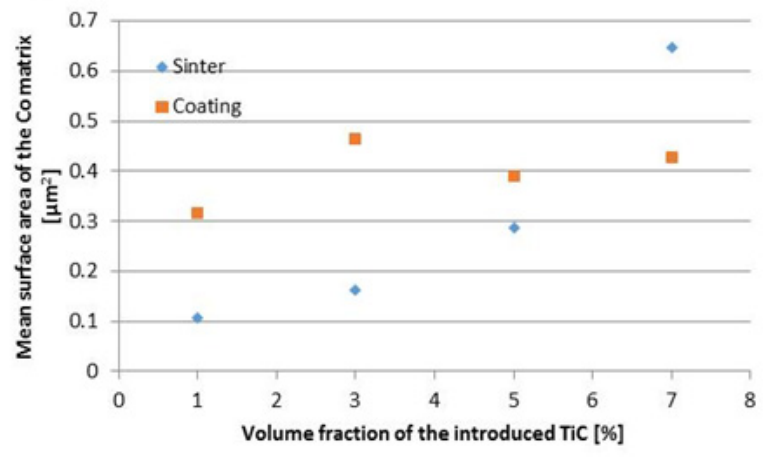

Fig. 9. The dependence of the volume fraction of introduced TiC and selected quantitative evaluation parameters; TiC volume fraction (a) and the mean surface area of TiC agglomerates (b), porosity volume fraction (c) and distance between the pores (d), Co matrix volume fraction (e) and it's mean surface area (f) 
TiC amount in WC-Co material type was investigated also. For the experimental results, the following conclusions can be drawn.

1. The addition of nano-sized TiC to the sintered material does not lead to the porosity decrease. On the other hand, nano-sized TiC modification of deposited coatings results in great porosity decrease. The porosity of the deposited coating with 7 wt. \% TiC addition is comparable to the porosity of sintered material prepared from the same powder mixture.

2. Addition of nano-sized TiC leads to increase of WC-Co materials hardness. The hardness of sintered material is higher than the deposited coating, which is caused by more homogenous distribution of the nano-sized $\mathrm{TiC}$ within the Co matrix.

3. The microstructure analyzes revealed a tendency to agglomeration of sub-micrometric $\mathrm{TiC}$ in sinters. In the sinter, the WC grains created the clusters which were surrounded by TiC agglomerates. Mentioned agglomerates were forming the cell microstructure.

\section{Acknowledgement}

We gratefully acknowledge the financial support from the research project no. BKM 523/ $\mathrm{RM} 0 / 2016$.

\section{REFERENCES}

1. Berger L. M., Application of hardmetals as thermal spray coatings, Int. J. Refract. Met. Hard Mater. (2015). doi:10.1016/j.ijrmhm.2014.09.029.

2. Bolelli G., Berger L. M., Bonetti M., Lusvarghi L., Comparative study of the dry sliding wear behaviour of HVOF-sprayed WC-(W,Cr) $)_{2} \mathrm{C}-\mathrm{Ni}$ and WC-CoCr hardmetal coatings, Wear. (2014). doi:10.1016/j.wear.2013.11.001.

3. Csanádi T., Novák M., Naughton-Duszová A., Dusza J., Anisotropic nanoscratch resistance of WC grains in WC-Co composite, Int. J. Refract. Met. Hard Mater. (2015). doi:10.1016/j.ijrmhm.2015.03.005.

4. Gorlach I.A., The Application of High Velocity Air Fuel Process for the Deposition Coatings, R\&D Journal 24 (2008).

5. Guilemany J.M., Dosta S., Miguel J.R., The enhancement of the properties of WC-Co HVOF coatings through the use of nanostructured and microstructured feedstock powders, Surf. Coatings Technol. (2006). doi:10.1016/j.surf- coat.2006.01.041.

6. Hulka I., Şerban V. A., Secoşan I., Vuoristo P., Niemi K., Wear properties of CrC-37WC-18M coatings deposited by HVOF and HVAF spraying processes, Surf. Coatings Technol. 210 (2012) 15-20. doi:10.1016/j.surfcoat.2012.07.077.

7. Jacobs L., Hyland M.M., De Bonte M., Study of the Influence of Microstructural Properties on the Sliding-Wear Behavior of HVOF and HVAF Sprayed WC-Cermet Coatings, J. Therm. Spray Technol. 8 (1999) 125.

8. Lin N., He Y., Wu C., Liu S., Xiao X., Jiang Y., Influence of $\mathrm{TiC}$ additions on the corrosion behaviour of WC-Co hardmetals in alkaline solution, Int. J. Refract. Met. Hard Mater. (2014). doi:10.1016/j. ijrmhm.2014.05.009.

9. Liu S., Sun D., Fan Z., Yu H.Y., Meng H.M., The influence of HVAF powder feedstock characteristics on the sliding wear behaviour of $\mathrm{WC}-\mathrm{NiCr}$ coatings, Surf. Coatings Technol. 202 (2008) 4893-4900. doi:10.1016/j.surfcoat.2008.03.014.

10. Mateen A., Saha G.C., Khan T.I., Khalid F.A., Tribological behaviour of HVOF sprayed near-nanostructured and microstructured WC-17wt.\%Co coatings, Surf. Coatings Technol. (2011). doi:10.1016/j.surfcoat.2011.07.075.

11. Milanti A., Matikainen V., Koivuluoto H., Bolelli G., Lusvarghi L., Vuoristo P., Effect of spraying parameters on the microstructural and corrosion properties of HVAF-sprayed $\mathrm{Fe}-\mathrm{Cr}-\mathrm{Ni}-\mathrm{B}-\mathrm{C}$ coatings, (2015). doi:10.1016/j.surfcoat.2015.07.018.

12. Myalska H., Moskal G., Szymański K., Microstructure and properties of WC-Co coatings, modified by sub-microcrystalline carbides, obtained by different methods of high velocity spray processes, Surf. Coatings Technol. 260 (2014) 303-309. doi:10.1016/j.surfcoat.2014.07.097.

13. Park S.Y., Kim M.C., Park C.G., Mechanical properties and microstructure evolution of the nano WC-Co coatings fabricated by detonation gun spraying with post heat treatment, Mater. Sci. Eng. A. 448-451 (2007) 894-897. doi:10.1016/j. msea.2006.02.444.

14. Poblano-Salas C., Cabral-Miramontes J., GallegosMelgar A., Ruiz-Luna H., Aguilar-Escobar J.D., Espinosa-Arbelaez D.G., Espinoza-Beltrán F., Trapaga-Martínez G., Muñoz-Saldaña J., Effects of $\mathrm{VC}$ additions on the mechanical properties of bimodal WC-Co HVOF thermal sprayed coatings measured by nanoindentation, Int. J. Refract. Met. Hard Mater. 48 (2015) 167-178. doi:10.1016/j. ijrmhm.2014.08.016.

15. Qiao Y., Fischer T.E., Dent A., The effects of fuel chemistry and feedstock powder structure on the mechanical and tribological properties of HVOF thermal-sprayed WC-Co coatings with very 
fine structures, Surf. Coatings Technol. (2003). doi:10.1016/S0257-8972(03)00242-1.

16. Rodríguez M.A., Gil L., Camero S., Fréty N., Santana Y., Caro J., Surface \& Coatings Technology Effects of the dispersion time on the microstructure and wear resistance of WC / Co-CNTs HVOF sprayed coatings, Surf. Coat. Technol. 258 (2014) 38-48. doi:10.1016/j.surfcoat.2014.10.014.

17. Stewart D.A., Shipway P.H., Mccartney D.G., Abrasive wear behaviour of conventional and nanocomposite HVOF-sprayed WC-Co coatings, Wear. 225229 (1999) 789-798.

18. Sudaprasert T., Shipway P.H., McCartney D.G., Sliding wear behaviour of HVOF sprayed WCCo coatings deposited with both gas-fuelled and liquid-fuelled systems, Wear. 255 (2003) 943-949. doi:10.1016/S0043-1648(03)00293-X.

19. Szala J., Instrukcja obsługi Met-Ilo, Silesian University of Technology, Gliwice, Poland, 2008; Repozytorium Publikacji Naukowych Politechniki
Śląskiej; oai:repolis.bg.polsl.pl:7579.

20. Upadhyaya G.S., CEMENTED TUNGSTEN CARBIDES Production, Properties, and Testing, (n.d.).

21. Xie M., Zhang S., Li M., Comparative investigation on HVOF sprayed carbide-based coatings, Appl. Surf. Sci. (2013). doi:10.1016/j.apsusc.2013.03.010.

22. Zeoli N., Gu S., Kamnis S., Numerical simulation of in-flight particle oxidation during thermal spraying, Comput. Chem. Eng. (2008). doi:10.1016/j. compchemeng.2007.08.008.

23. Zhang S., Sun D., Fu Y., Du H., Toughening of hard nanostructural thin films: A critical review, Surf. Coatings Technol. (2005). doi:10.1016/j.surfcoat.2004.10.020.

24. Żórawski W., The microstructure and tribological properties of liquid-fuel HVOF sprayed nanostructured WC-12Co coatings, Surf. Coat. Technol. 220 (2013) 276-281. 